\title{
DOUTRINA
}

\section{FILOSOFIA DO DIREITO COMO PROBLEMA FILOSÓFICO (")}

ANTONIO JOSÉ BRANDÃO

\section{PRIMEIRA APROXIMAÇÃO DO PROBLEMA}

1. Teoria da verificação teórica - Qualquer verificação teórica permanece encerrada no círculo descrito ao efectuar-se. Coincide com o ponto de partida o seu ponto de chegada: os aspectos pelos quais certo existente manifesta a verosimilhança na situação em que se encontra conosco.

Percorrendo este trajeto inevitável, diligenciamos transitar de uma relação menos favorecida para outra mais favorecida.

Podemos encontrarmo-nos na primeira quando inesperadamente, sem motivo claro, deixamos de contar com esse existente como até então o havíamos feito. Pois uma vez liberto das convicções reinantes, que the asseguravam posição significativa no nosso mundo, dir-se-ia que seu vulto aparecente remergulha nas sombras originárias, resistindo-nos e criando-nos uma situação de perplexidade, como a tradição platônica-aristotélica a interpreta, ou uma situação de consciência dilacerada, como a tradição hegeliana a caracteriza. À segunda podemos chegar, não sem deliberado e consciente esforço mental, se conseguirmos entretanto, a partir dessa situação, pensarmos outros pensamentos cuja referência intencional se lhe dirige. Só assim iremos projetando sobre ele algumas evidências racionais que, ao iluminarem-nos, o luminam. Na relação nova, se o nosso dizer se ajustar à verosimilhança do existente, interpretando-a pelos conceitos que a descrevem, cuidamos então surpreendê-lo no acto de patentear o próprio ser ou de se apresentar revestido da própria verdade.

(*) Comunicação elaborada em 1948 para um Congresso Internacional de Filosofia. Boletim da Faculdade de Direito da Universidade de Coimbra, n. XLVI - 1970. 
Com semelhante regresso ao ponto de partida, esgota-se momentâneamente a verificação, - a qual, em derradeira análise, corresponde ao produto da função verificadora que a nossa vida também pode assegurar quando é vivida à luz da razão teórica. A importância dela não está apenas em nos proporcionar notícias, saberes ou conhecimentos do existente verificado. Está sobretudo no facto de nos oferecer a possibilidade de o termos diante de nós tal como parece ser em sí enquanto diligenciamos viver verdadeiramente a seu respeito. Verificar equivale à tentativa de ficar no vero; e ficar no vero é o eventual resultado da verificação.

No entanto, essas notícias, esses saberes ou conhecimentos também se acumulam em nós como esquemas que podem dar estrutura, forma, sentido, a nossa conexão mental com o existente. Exprimem - que vamos sendo enquanto seres capazes de pensar pensamentos dirigidos ao existente - e o que nos vai revelando o existente quando o encontramos nas sucessivas situações em que temos de viver.

2. Objectivo da presente verificação - A Filosofia do Direito, tal como se apresenta na nossa situação, - onde se encontra definitivamente restaurada desde 1930 no parecer de muitos autores, - eis o ponto de partida desta verificação. Constitui, por conseguinte, o seu necessário ponto de chegada. Se esta tarefa só hoje se mostra indispensável, é porque só agora se começa a reparar no seguinte: a Filosofia do Direito está aí como um verosimil ainda por verificar.

O homem europeu, desde o final do século passado ao começo do nosso, entregou-se à tarefa de a restaurar. Fruto de semelhante esforço, ela é hoje uma das suas típicas criações e actividades. Mas ao contrário do que se julgou, e tão superficialmente, por vezes, não se tratou de mero restabelecimento de tradição obliterada ou enfraquecida por qualquer peripécia histórica. Restaurar, em sentido especificamente humano, envolve sempre o acto de refundar, de voltar a erguer o edifício dos seus alicerces. Neste caso, note-se bem, os alicerces são a nossa própria vida, que está decorrendo no mundo em que the coube ser vivida, diferente, segundo parece, do mundo do passado, alheio à Filosofia do Direito. Consentindo outra vez em dar viço à Filosofia do Direito, a nossa vida deve estar a receber por troca algo que lhe faltava e agora a completa. O quê?

Eis pergunta bastante embaraçosa. Neste preciso momento, estamo-nos dedicando à Filosofia do Direito sem ao certo sabermos o que fazemos quando nela consumimos vida - nem ao certo sabermos o que ela representa na nossa vida. São equívocas as nossas 
relações: pois mal sabemos o que ela em sí é e o que somos quando usamos dela. O acontecimento, por estranho, impressiona. Está todavia sucedendo assim mesmo.

3. Presença da Filosofia do Direito - Desde o fim do século passado, a vida humana entrou a imaginar-se de tal modo que possibilitou o regresso e a persistência da Filosofia do Direito. O facto de nos dedicarmos a uma meditação filosófico-jurídica, ou de nos servirmos de uma obra filosófico-jurídica, voltou a ter sentido em princípio compreensível. Pois de nós, do nosso momentâneo projecto de vida, depende a interpretação do que representam para nós os existentes quando temos de lidar contando com eles, a fim de diligenciarmos ser quem somos. Mas o esquema genérico desta pretensão a ser já se encontra preformado e actuante no quotidiano em que a nossa vida decorre.

Com efeito, curso da nossa vida e quotidiano são duas realidades distintas, embora intercondicionadas. A procissão contínua dos "nossos dias" confunde-se com o trânsito temporal que, do nascimento à morte vai constituindo a nossa vida. Mas o decurso vital de cada um de nós só no quotidiano adquire sentido humano e mundano.

Quotidiano aponta para o dia-a-dia daquilo a que também chamamos "mundo": as convicções em que estamos acerca de todos os seres com os quais lidamos ao viver, sem excluir as convicções acerca de nós próprios e do nosso lugar na Terra. Daqui promana a interpretação imediata em que a vida humana se vai configurando enquanto de si mesma e do seu decurso, vivendo, revivendo e previvendo, adquire uma experiência, possível via de auto-orientação neste mundo, recolhida e decantada pela tradição e pela linguagem.

Quotidiano é, pois, o mesmo que "mundo quotidiano": um saber da vida acerca dela mesma, - saber imediato, afectivo, difuso, expresso por um sistema de convicções socialmente em vigor e, por isso mesmo, tão arraigadas na maneira de ser de todos nós, que todos nós, ao vivermos, as projectamos sobre o existente, identificando-as com o rosto que o existente nos descobre todos os dias. Aqui manifestam também os seres uma presença vacilante, interina, mas, ao mesmo tempo, efectiva e concreta.

No "mundo quotidiano", em princípio igual para todos e por todos compartilhado, adquire o curso da nossa vida certo grau de inteligibilidade que the serve de fio orientador enquanto the permite ser de certo modo. Por sua vez, a verosimilhança dos seres 
obtém aí certo grau de significação que proporciona à nossa vida a possibilidade real de contar com eles por uma maneira condizente com ela. A co-imersão no "mundo quotidiano", imprimindo também um sentido aos nexos que os homens estabelecem entre si e com os outros seres, torna-os a todos naturais deste "nosso mundo".

No nosso mundo quotidiano, a Filosofia do Direito restaurada apresenta-se, em primeiro lugar, na esfera dos seres apreensíveis pelos sentidos externos: cátedras universitárias academias ou seminários, livrarias, livros e revistas. Todas estas realidades, enquanto The fornecem um suporte à sua auto-apresentação, também são abrangidas pela sua noção genérica e usual e só referidas a ela denotam um sentido para nós. O seu conjunto representa, na terminologia de Dilthey, um sistema cultural. Neste caso, o sistema cultural da Filosofia do Direito, parte de um todo mais vasto, o sistema cultural de cada nação.

Um saber ou afazer tende a organizar-se em sistema cultural sempre que o convencimento da sua utilidade para a vida em comum se propaga no ambiente ou actua fortemente, pelo menos, sobre os grupos investidos no poder de mandar. Assim parece ter acontecido à Filosofia do Direito, cujo ensino universitário foi tornado obrigatório em quase todos os países. Em que medida o reconhecimento desta sua função social responde a necessidades efectivas dos organismos que se mantêm com a forma política e jurídica de Estados nacionais no âmbito da Cultura do Ocidente, eis aspectos pouco esclarecido do fenômeno apontado. Por agora, interessa apenas outro aspecto digno de nota: a obrigação legal de frequentar a cadeira de Filosofia do Direito origina entre o professor e os alunos uma conexão social em que se praticam actos - os actos de expor e de ouvir - pelos quais também acontece a Filosofia do Direito. Uma conexão social do mesmo gênero se estabelece entre os filiados de qualquer instituto privado de Filosofia do Direito, ou entre os mesmos e o público em geral, destinatário das reuniões abertas ou das obras postas a circular. Bibliotecas, editoriais, livrarias de Filosofia do Direito, encontram também a sua justificação nestas relações sociais. Delas ainda depende o próprio centro criador da Filosofia do Direito, pois fornecem a possibilidade de tornar pública a meditação a que se entrega o homem a quem dói o amor à sabedoria jurídica. E como essa meditação é dita por palavras orais ou escritas, cujo sentido só pode ser apreendido por quem as ouvir ou ler, segue-se que esta rede de conexões sociais, em última análise, é o sustentáculo eventual da própria Filosofia do Direito enquanto sistema de proposições ou enunciados filosófico-jurídicos. 
Mas a Filosofia do Direito não se apresenta no nosso quotidiano apenas como sistema cultural, como rede de conexões sociais, como vocação pessoal e como teoria ou conjunto hierarquicamente ordenado de proposições filosófico-jurídicas. A sua manifestação concreta, mediante todas estas formas de se auto-apresentar, está condicionada pelo papel brilhante ou obscuro que the foi secretamente reservado pelo nosso projecto de vida. O sentido mundano e humano da sua realidade exprime-se com a máxima nitidez na nossa maneira de ser para com ela. Os nossos comportamentos e apreciações fornecem o índice preciso do lugar que ela ocupa na nossa vida e da margem de auto-doação que a nossa vida lhe reserva.

Ora os estudantes universitários, tirando alguma excepção rara, estudam Filosofia do Direito porque não têm outro remédio. O professor catedrático ensina-a por vocação ou ofício no meio da indiferença ou da hostilidade dos restante colegas. A actividade dos Institutos de Filosofia do Direito inscreve-se em círculos muito estreitos de interessados. A maioria dos jurisconsultos nada confia da Filosofia do Direito, nem espera dela qualquer luz para as suas preocupações teóricas ou práticas. A própria vocação filosófica do jurisconsulto nenhum estímulo recebe do ambiente quotidiano, que a rodeia de falsa consideração ou a deprecia por the negar qualquer utilidade, perturbando-a ou recusando-lhe prestígio social.

No nosso projecto de vida e na nossa situação histórica, que contam, entre os seus elementos constitutivos, a Filosofia do Direito restaurada. esta surge como realidade dúbia. Ao menos perpicaz não escapam neste momento duas pretensões contraditórias a propósito dela. Por um lado, a da maioria, negadora da sua eficácia como conhecimento teórico do Direito, da sua missão de reitora da ciência dogmática do Direito, da sua vantagem na solução dos problemas jurídicos trazidos pela vida convivida. Por outro lado, a da minoria, convicta da sua forçosa necessidade, exigida pela própria natureza do espírito humano, a qual reclama também da meditação filosófica do Direito a definição de certos valores, de certas normas, de certos fins e de certas condutas do homem convivente. Desta sorte, apesar da Filosofia do Direito restaurada estar aí como sistema cultural, como função social e como vocação pessoal, não se pode afirmar dela que existe, no sentido histórico e social do verbo existir: impondo-se à imaginação, ao intelecto e à vontade da generalidade dos homens. Neste preciso momento, embora pareça absurda a afirmação, a Filosofia do Direito é cultivada, mas não vigora. A nossa vida não se comporta ante ela do modo pelo qual se comporta ante realidades incontestadas. Nenhuma hesitação a estremece 
quanto ao valor e ao sentido da ciência e da técnica jurídicas, por exemplo. Continua a acreditar em ambas e a aceitá-las como energias espirituais conformadoras da sua maneira actual de ser. $\mathrm{Na}$ comprensão científica ou técnica do Direito encontra, de algum modo, directa interpretação de si própria. Ao mesmo tempo, sente que a Filosofia do Direito Ihe escapa, ou exprime teoricamente o Direito a grande distância do campo onde ela luta por se afirmar e ser.

4. Filosofia do Direito como problema filosófico - A Filosofia do Direito restaurada ainda não foi aparentemente recebida pelo "nosso mundo", pelo sistema de convicções dominantes, ao ponto de pertencer ao conjunto de vigências em que se está, e cuja articulação funcional, a partir da perspectiva unificadora fornecida pela íntima sensibilidade vital de cada geração, constitui uma época, a forma concreta assumida pela vida humana no seu decurso histórico. O facto de se ter dado novamente ao catedrático a possibilidade de preleccionar Filosofia do Direito prova apenas que se reconheceu a este ensino determinado relevo político e pedagógico. No entanto, nem afiança a genuidade da Filosofia do Direito, nem o âmbito da sua influência social. O facio de novamente se publicarem tratados, monografias, manuais ou revistas de Filosofia do Direito, ou de se fazerem conferências e congressos, também nada esclarece quanto à verdadeira índole dela, nem quanto ao seu verdadeiro lugar na nossa vida, por grandes que sejam as tiragens e por largos que sejam os auditórios. Em todos estes factos, a Filosofia do Direito, ao acontecer, ambiciona manifestar-se como tal. Enquanto revelam a sua pretensão a ser, aludem ao que ela em si mesma é. Nesta alusão, contudo, não conseguimos nós ainda abrirmo-nos para a sua essência de típica criação nossa, nem descobrir quem somos ao criá-la e ao mantê-la. Pois a prefiguração actual da nossa vida, se nos dá a possibilidade concreta de nos dedicarmos à Filosofia do Direito, não se inspira, contudo, de nítida idéia dela. Esta sua deficiência ou lacuna foi entretanto preenchida pelo convencimento, dominante no nosso mundo quotidiano, de que a Filosofia do Direito corresponde a luxo da teoria sem raízes na nossa vida. Ela não está aí, restaurada na nossa situação, com a naturalidade ou a șingeleza das tarefas ou coisas que, por evidentes, ninguém discute e a todos oferecem sentido claro. A sua presença, alimentando-se da própria luta de convicções a propósito da sua essência e existência, é tão estranha como instável e constitui para nós um problema vital e teórico. Urge averiguar, por conseguinte, o que a Filosofia do Direito é, quais as causas dos seus periódicos aparecimentos e desaparecimentos. Por outro lado, urge ainda indagar o que a nossa vida pretende ao retomar a 
Filosofia do Direito - e como, e em que medida, a Filosofia do Direito influencia na nossa vida, contribuindo para a sua efectiva configuração histórica.

\section{SEGUNDA APROXIMAÇÃO DO PROBLEMA}

5. Saber imediafo do existente e função ontológica da linguagem - As nossas convicções espontâneas, enquanto iam despontando em nós, outorgaram o crédito necessário ao regresso e à persistência da Filosofia do Direito. Mas hoje, abaladas pelas dúvidas entretanto surgidas, cederam o lugar ao "não saber ao certo" actual terreno movediço da nossa compresença. A Filosofia do Direito, - notamo-lo agora, admirados, - também se mantém latente ou oculta nas próprias actividades e obras humanas a que adere o intuito de a patentear ou declarar. Postos conscientemente perante facto tão insólito, formulamos para nós mesmos a pergunta: que é então, a Filosofia do Direito?

Quando o homem chega ao extremo de ter de repetir pergunta tão antiga e sempre tão inédita, sente-se já compelido a mobilizar a faculdade de pensar, a fim de substituir a perdida convicção espontânea por convicção de outro tipo: aquela a que pode chegar usando propositadamente da razão e dos meios racionais de adquirir saber dos aspectos enigmáticos da sua situação. A este resultado eventual, chamamos também, desde há muitos séculos, conhecimento. Nós sentimo-nos hoje compelidos a tentar conhecer o que a Filosofia do Direito é, - pois só do momento em que a razão teórica descobrir a razão de ser dela estaremos nós aptos a contemplá-la desde a convicção racional do sentido e da função que ela, como específica criação e actividade nossa, tem na nossa vida.

Mas o saber proveniente do conhecimento apenas fundamenta, com outros meios e em outro plano, o saber imediato aprendido pela nossa vida enquanto foi sendo vivida. Só se chega a conhecer - já sabido; daqui, não da ignorância absoluta, arranca o conhecimento. Pois o já sabido faz parte do nosso mundo quotidiano, embora ninguém repare nele, exactamente por todos o darem por já sabido ou subentendido.

Da Filosofia do Direito também possuímos já um certo saber imediato: aquele mesmo que, hoje, se nos depara como um "não saber ao certo". O depósito secular deste saber é a linguagem, que não criamos, e já encontramos pronta para o uso quando tivemos de aprender a utilizá-la na exteriorização do que vamos sendo ao encontrarmo-nos com os seres, e entre os seres, do nosso mundo 
quotidiano. Se ela nos serve ainda de meio de intercomunicação mundana, é porque funciona, em primeiro lugar, como interpretação verbal da realidade por nós vivida. Nesta interpretação estamos nós também interpretados, pois a linguagem funda-se na nossa vocação ontológica e discursiva, na capacidade natural de nos abrirmos à compreensão do ser do existente e de a dizermos pela palavra.

Pela linguagem, que permite aos homens dizerem entre si 0 que as coisas são, adquirem as coisas a possibilidade de se apresentarem aos homens tal qual são. $O$ ser e os modos de ser do existente declaram-se também pelo modo de ser e pelo dizer desse existente a quem foi dado por em palavra o sentimento da originária inserção na ordem divina e cósmica, que liga os existentes entre si por invisíveis e subtis laços de amor. A linguagem é a raiz metafísica do nosso mundo quotidiano e de quanto nele há ou se manifesta; é a fonte primária da significação e da inteligibilidade, da ontologia espontânea que publicamente vai exprimindo e tornando socialmente vinculativa a nossa compreensão imediata da realidade circunstante.

6. Conteúdo ontológico do nome "Filosofia do Direito" Devido à própria natureza e função, o nome contribui fundamentalmente para o aparecimento do nomeado no nosso mundo, embora jamais o substitua ou elimine com uma palavra. A sua eficácia designativa, proporcionadora de presença como o reconhecem os rituais da magia e da religião, apenas se corrompe no uso corrente da linguagem. A comum interlocução, que nos exprime nas situações normais da vida convivida, tende a repousar na significação convencional das palavras, esquecida de que a origem delas foi mencionar as coisas significadas por seu intermédio.

Mas cada nome é descoberto e divulgado dentro de círculo vicioso inevitável. Ele designa a essência ainda desconhecida que o sugeriu misteriosamente; uma vez criado e adoptado, nomeia-a, fornecendo uma primeira interpretação do existente em seu ser, núcleo germinal da etimologia, da mitologia e da ontologia. O continuado uso, lançando-o no domínio público, socializa esta interpretação, que adquire zona de aplicação coincidente com a zona de apresentação do existente nomeado. Socializa também a referência intencionalmente significativa do nome. Tal conteúdo ontológico permite-lhe chamar - nomeado ao seu campo de exposição e, simultaneamente, dá-lhe a possibilidade de guiar para aqui a visão do nomeador.

A frase que, pelo baptismo, a identifica, assinala a presença 
da Filosofia do Direito no nosso mundo quotidiano. Filosofia do Direito, como nome, integra a Filosofia do Direito, como fenômeno. Quando se repara na composição deste nome, relacionando-a, depois; com o nomeado, fica-se perante um existente, que dir-se-ia resultar da particular combinação de dois outros existentes: a Filosofia e ○ Direito. A preposição "do" insinua até a forma dessa reunião, já que nos inculca a noção de que o Direito pertence à Filosofia, ou de que esta exerce sobre aquele acção apropriadora. Filosofia da Religião, Filosofia da Arte, Filosofia da História, Filosofia da Ciência. Filosofia da Política, - eis outros tantos nomes que designam outras tantas interpretações iniciais de realidades ônticas afins da Filosofia do Direito. Qualquer deles alude ao existente cujo ser a Filosofia tenta dizer segundo o modo peculiar da sua dicção. A "Filosofia de...", antes de mais nada, é Filosofia. O existente de que se ocupa, faz parte dela, no entanto, porque a preocupa como problema do filosófo, que o vive, sente a medita na situação em em que está.

Na medida em que a palavra já conseguiu nomeá-lo, cai o existente na esfera de influência dos nossos saberes e das nossas convicções dominantes, - estrutura objectiva, que vai imprimindo uma forma ao nosso decurso vital, enquanto de nós recebe a vitalidade que a sustenta e modifica imperceptivelmente. Nesta esfera estamos nós vivendo como seres abertos por natureza à compreensão do existente - e está o existente patenteando-se, oferecendo-se-nos na genuidade do seu ser. $O$ nome, que lhe dá ingresso no nosso mundo quotidiano, predetermina também o processo da sua pública man'festação e das nossas diligências sucessivas de o compreender. Pela sua presença, está o existente denunciando-se à palavra enunciadora; e esta, ao mencioná-lo, derrama sobre ele a claridade do espírito, até à fronteira momentânea das trevas originárias, onde tudo se indefine e oculta. Descobrindo a maneira de nomear e de dizer - existente, o homem adquire a possibilidade de o ver na sua realidade ou verdade.

Filosofia e Direito, existentes que há muitos séculos já conseguimos nomear, são-nos tão familiares como estranhos. Qualquer pessoa de mediana cultura não encontra dificuldade imediata na apreensão do sentido de frases compostas com qualquer destes nomes. Assim the acontecerá se ouvir ou ler que a vida é a mestra da Filosofia; que a Filosofia de Kant ainda possui adeptos; que a Escolástica foi a Filosofia da Idade Média; que os gregos criaram uma Filosofia, matriz da Filosofia do Ocidente. Cada uma destas frases, porém, utiliza a palavra Filosofia em acepção diferente. $O$ saber da 
Filosofia, entretanto acumulado pelo nome que a designa, difundiuse a tal ponto no meio social que permite já, nas conexões de sentido lógico das frases em que entra, importantes e subtis variações da capacidade nomeadora. Nas locuções citadas, o mesmo nome, - Filosofia -, indica diversos aspectos da Filosofia como fenómeno: a sageza ensinada pela meditação da experiência da vida; a obra ou o sistema de certo filósofo; a forma histórica predominante assumida pela Filosofia em certa época; a Filosofia de certo povo, em dado momento do seu decurso histórico.

Algo de semelhante se passa com o Direito. Nenhuma dificuldade terá $\circ$ homem de cultura mediana em figurar o sugerido pelas frases seguintes: tenho direito a que me respeitem a pessoa e os bens; $\circ$ Direito vigente; o Direito português. Tais frases, contudo, resumem já um saber bastante amadurecido do Direito e nele se descortinam vários aspectos: o subjectivo, o objectivo e o nacional.

Quer dizer: o nosso actual não saber ao certo da Filosofia e do Direito pressupõe, em vez de o excluir, o nosso saber espontâneo, imediato, difuso, da Filosofia e do Direito. Este saber imediato, préteórico, adquirido e apurado nas diferentes circunstâncias em que decorreu a vida convivida, encontra-se na origem da nomeação destes existenies e dos juízos da realidade ou de valor que vão interpretando a maneira como nos relacionamos com eles.

Mas não é ainda suficientemente rigoroso e profundo para nos habilitar a responder às perguntas, que, em certa medida, também provoca e condiciona: que é Filosofia? Que é Direito? Que é Filosofia do Direito?

Também com outros nomes nos sucede o mesmo. Alma, consciência, liberdade, justiça, tempo, eis palavras a todos familiares. Se ninguém nos perguntar o que mencionam, todos julgamos sabêlo; e, de facto, todos possuímos destes existentes um difuso saber comum, apto a guiar-nos nas situações da vida ordinária. Só em situações extraordinárias podemos reparar, de súbito, que eles, afinal, são o que são, em vez de serem o que sempre se julgara. Isto é: podemos reparar no carácter interino superficial, lacunar, contraditório, inadequado do nosso difuso saber comum. Ficamos então com esses existentes numa relação em que eles se mostram incompreensivelmente capazes de se alterarem ou ocultarem à nossa vista. Esta situação extraordinária provoca a pergunta, igualmente extraordinária: que é isto? É o momento medial entre a ontologia espontânea e a ontologia teórica ou Filosofia. É o momento em que se rompe o acordo social, alimentado pela aceitação tácita e corrente do "nosso mundo", em cuja estrutura objectivada todos os seres vão 
adquirindo um significado de harmonia com a interpretação recolhida pela linguagem herdada, que até então também interpretava a nossa sensibilidade e a nossa razão, quando funcionavam ligadas ao acto sucessivo de viver a vida. Dir-se-ia que, de repente, a linguagem se torna inapta ou ineficaz para dizer o ser do existente, roubando-nos a possibilidade de o sentir e de o pensar. A consciência dilacerada corresponde sempre à consciência dolorosa que nos revela, junto ao nosso impulso ontológico, a lacuna do nosso dizer: faltanos o "mundo" no preciso instante em que dele solicitávamos orientação segura acerca de algo que nele está conosco. Mas a mental aritude designada há séculos pelo nome surpreendente de Filosofia tem-se manifestado até hoje pelo ensaio, sempre frustrado e sempre recomeçado, de restabelecer, em outro plano e com outro alcance, a aliança do pensar e da palavra com o existente em seu ser e com o ser enquanto ser.

Se nos damos agora conta de que carecemos de um Direito contemplado e definido segundo o modo peculiar à Filosofia, temos $d$ admitir a presente insuficiência do nosso saber jurídico, tanto a do espontâneo como a do reflectido. De facto, hoje ainda, como no tempo de Kant, o jurisconsulto anda à procura do conceito de Direito.

Mas teremos já suficiente saber da Filosofia que nos há-de ministrar tal saber do Direito?

7. Filosofia da Filosofia do Direito. A pergunta, em toda a sua radicalidade, surge hoje inevitavelmente à mente de quem pietenda meditar sobre o Direito. Quer o jurisconsulto de vocação filosófica, quer o filósofo de vocação jurídica andou até agora diligenciando interpretar filosoficamente um existente que continuava a resistir-ihe como problema, - o Direito -, mediante uma actividade mental, - a filosofia -, que ainda não conseguiu plenamente justificar-se perante a vida, - e, por isso, é para muitos uma activide equívoca. Sobre esta descoberta impressionante pesa o enigma da Filosofia e da sua história. Filosofia da Filosofia chamou Dilthey à dramática tomada de consciência deste fato e a não menos dramática tentativa de autognose da Filosofia pela Filosofia.

Filosofia da Filosofia do Direito será a tarefa que o jurisconsulto de vocação filosófica terá de realizar quando se aperceber que está por averiguar a essência da Filosofia - e o esquecimento do Direito pela Filosofia do Direito. Até hoje, a Filosofia do Direito aceitou-se a si própria como uma evidência e considerou-se em dificuldade por causas alheias a ela, - a pretensa decadência da cultura ocidental, 
a pretensa fraca espiritualidade dos tempos correntes e as pretensas consequências ideológicas das modificações da estrutura econômica. Por outro lado, até hoje, a Filosofia do Direito, em vez de se colocar em frente do Direito, tem preferido meditar nexos em que o Direito permanece oculto: os nexos entre lei divina, lei natural e lei positiva, entre justiça e direito positivo. 